\section{Embolismos sépticos \\ pulmonares paradójicos en \\ paciente con endocarditis sobre \\ válvula aórtica y comunicación \\ interventricular: la puerta de \\ atrás}

\section{Septic paradoxical pulmonary embolisms in a patient with aortic valve endocarditis and interventricular communication: the backdoor}

\section{Presentación del caso}

La endocarditis es una enfermedad que se produce como resultado de un proceso inflamatorio localizado en el revestimiento interno de las cámaras y válvulas (bien sean nativas o protésicas) cardiacas. En España, la incidencia estimada de endocarditis infecciosa (EI) es entre 3.1-3.7 episodios por cada 100,000 habitantes/año, siendo los estafilococos, los estreptococos y los enterococos, los responsables de la mayoría de los casos $^{1}$.

Exponemos el caso de una paciente con una cardiopatía congénita (comunicación interventricular), que ingresa para estudio de nódulos pulmonares y fiebre. Lo excepcional de nuestro caso es que se le diagnostica de endocarditis bacteriana con una lesión vegetante en la válvula aórtica causante, a través de su comunicación interventricular, de embolismos sépticos pulmonares, sin ninguna otra afectación sistémica.

Mujer de 52 años sin alergias medicamentosas conocidas, ni intervenciones quirúrgicas. Fumadora activa con un índice: 4 paquete/año. Refería antecedentes de bronconeumonía en la infancia, con supuestas imágenes cicatriciales residuales, que no sabía precisar. Sin antecedentes familiares de cardiopatías congénitas ni de enfermedades del sistema endocrino. En seguimiento por cardiología por pequeña comunicación interventricular restrictiva y aneurisma del septo membranoso diagnosticada hace más de 20 años, con hipertensión pulmonar ligera, pero asintomática, y sin repercusión hemodinámica. En el 2004 se le aconsejó profilaxis de endocarditis infecciosa y cierre del defecto, pero lo rechazó.

La paciente refería el inicio del cuadro 6 meses antes, consistente en tos seca y febrícula vespertina. Acudió a su médico de atención primaria 3 meses después por persistencia de la sintomatología y este solicitó radiografía $(\mathrm{Rx})$ de tórax interpretada como neumonía en resolución versus proceso específico activo. Se realizó prueba de tuberculina con resultado negativo y se instauró tratamiento antibiótico, consiguiendo completa remisión clínica, pero recurriendo la fiebre a los 20 días. Durante ese tiempo, acudió al dentista para colocar ortodoncia, donde fue nuevamente tratada con antibiótico (amoxicilina $1 \mathrm{~g} / 8 \mathrm{~h} / 7$ días). De nuevo remitió la fiebre, con reaparición 15 días después.

En la Rx de tórax de control se objetivaron posibles seudonódulos, por lo que ingresa en neumología para terminar el estudio. La paciente presentaba buen estado general, con saturación de oxígeno basal de $98 \%$, temperatura de $38.2^{\circ} \mathrm{C}$ y frémito yugular. A la auscultación cardiaca destacaba un soplo pansistólico, escuchándose con mayor intensidad en tercer y cuarto espacio intercostal, línea paraesternal izquierda, que se irradiaba a cuello. La auscultación pulmonar, así como la exploración abdominal y de extremidades inferiores eran normales. No se objetivaron alteraciones en piel o mucosas.

En la analítica aparecía una hemoglobina de $9.2 \mathrm{~g} / \mathrm{dl}$, no presente en analítica previa y una velocidad de sedimentación globular (VSG) elevada de $120 \mathrm{~mm}$, siendo normales la coagulación y el sedimento de orina. En el estudio de inmunidad se objetivó una PCR elevada: $2.15 \mathrm{mg} / \mathrm{dl}$ y una beta-2-microglobulina elevada: $3.37 \mu \mathrm{g} / \mathrm{ml}$. Las inmunoglobulinas IgG e IgM también estaban ligeramente elevadas: $1,900 \mathrm{mg} / \mathrm{dl}$ y $301 \mathrm{mg} / \mathrm{dl}$, respectivamente, así como el factor B del complemento: $47.7 \mathrm{mg} / \mathrm{dl}$. Todos los autoanticuerpos fueron negativos, así como normales los inmunocomplejos circulantes. Se realizó, también, fondo de ojo que descartaba foco infeccioso, y serologías para Salmonella y Brucella negativas.

Se realizó tomografía axial computarizada (TAC) de tórax, confirmando seudonódulos de contorno mal definido, inferiores a $10 \mathrm{~mm}$ de diámetro y situados a nivel subpleural, pudiendo contabilizar al menos 4 lesiones en hemitórax izquierdo y otras 2 de menor tamaño en el derecho (fig. 1). Las imágenes no presentaban características semiológicas que permitieran el diagnóstico por sí mismas.

Dados los antecedentes de la cardiopatía congénita y la fiebre sin foco aparente, se solicitaron hemocultivos seriados y ecocardiograma transtorácico (ETT). En dicho ETT se objetivan, además de las lesiones ya conocidas (aneurisma del septo membranoso con pequeña comunicación interventricular subaórtica e infracristal, sin signos de sobrecarga hemodinámica y ligera hipertensión pulmonar), imágenes sugestivas de lesión vegetante en válvula aórtica, por lo que se realizó ecocardiograma transesofágico que confirmó el diagnóstico de vegetación móvil de $5.5 \times 2.6 \mathrm{~mm}$ en cara ventricular de velo coronario izquierdo de válvula aórtica (fig. 2). Se inició tratamiento empírico con ceftriaxona $2 \mathrm{~g} /$ día y vancomicina $1 \mathrm{~g} / 12 \mathrm{~h}$. Tres días después, tras el aislamiento de Streptoccocus sanguinis (grupo viridans) en los hemocultivos seriados y, siguiendo el antibiograma, se sustituye la vancomicina por gentamicina a dosis de $3 \mathrm{mg} / \mathrm{kg} /$ día manteniendo la gentamicina durante las primeras 2 semanas y la ceftriaxona hasta completar un mes. La fiebre desapareció prácticamente desde el inicio del tratamiento. Los electrocardiogramas permanecieron siempre en ritmo sinusal sin alteraciones de la repolarización. La evolución analítica fue también favorable, con disminución de la VSG hasta $56 \mathrm{~mm}$ y aumento de la hemoglobina a $11.7 \mathrm{~g} / \mathrm{dl}$.

Valorada en consultas de cardiología al mes y medio, estaba afebril y asintomática. En la TAC de control se objetivaba la desaparición de las imágenes nodulares y la analítica mostraba normalización de hemoglobina y descenso de VSG a $40 \mathrm{~mm}$. Confirmándose de ese modo la desaparición de las lesiones pulmonares tras el tratamiento adecuado de endocarditis.

El diagnóstico principal es de El por Streptoccocus sanguinis sobre válvula aórtica, con embolismos sépticos pulmonares paradójicos a través de comunicación interventricular membranosa restrictiva.

En la actualidad, las El producidas por Staphylococcus aureus suponen la etiología más frecuente en el mundo, 

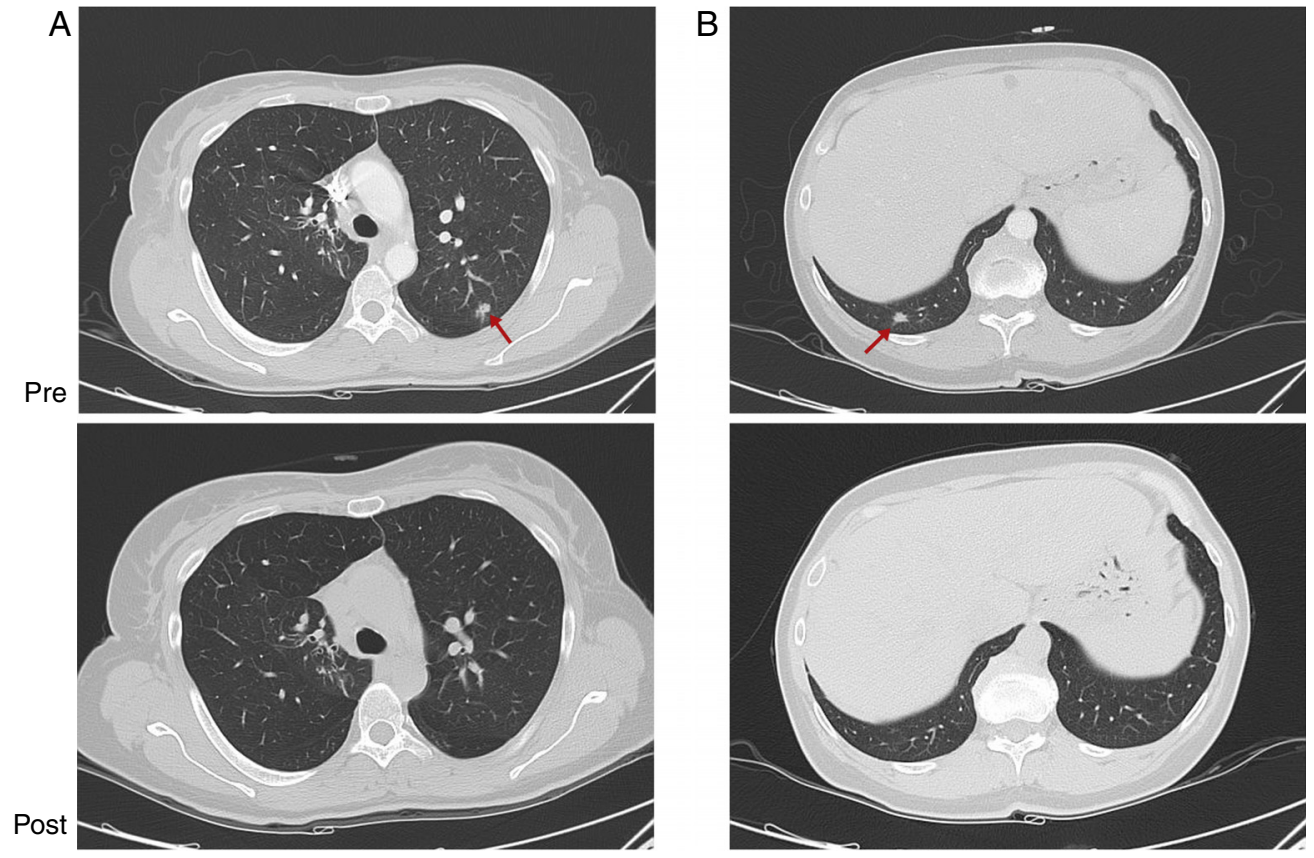

Figura 1 TAC torácico, con cortes realizados a nivel de ambos lóbulos superiores (A) y en lóbulos inferiores (B), donde se aprecian en el estudio previo al tratamiento (PRE), nódulos pulmonares bilaterales (flechas) que han desaparecido en las imágenes de control (POST).

aunque en Sudamérica, los estreptococos del grupo viridans son los gérmenes predominantes ${ }^{2}$. Se debe sospechar la presencia de El en las siguientes situaciones: paciente con fiebre sin focalidad infecciosa aparente, paciente febril con soplo cardiaco y paciente con fiebre y fenómenos embólicos (infarto, hemorragia) o lesiones cutáneas (estigmas de endocarditis). En nuestro caso, la paciente se encontraba realizándose un proceso dentario de larga evolución $y$, aunque no podía concretar la fecha exacta de su anterior visita, recordaba que era previa a la aparición de la clínica y que no había realizado profilaxis antibiótica.
Cuando se afectan las cavidades cardiacas derechas, el cuadro clínico es menos grave desde el punto de vista hemodinámico que el resto de formas de endocarditis y, en lugar de fenómenos embólicos sistémicos, son típicas las embolias sépticas pulmonares.

La asociación de endocarditis sobre válvula aórtica, con comunicación interventricular y embolismos sépticos pulmonares ha sido reflejada en una sola ocasión en la literatura, aunque en aquel paciente se produjo también embolismos a nivel sistémico ${ }^{3}$. Se ha descrito otro caso de embolismos pulmonares paradójicos de endocarditis sobre válvula aórtica
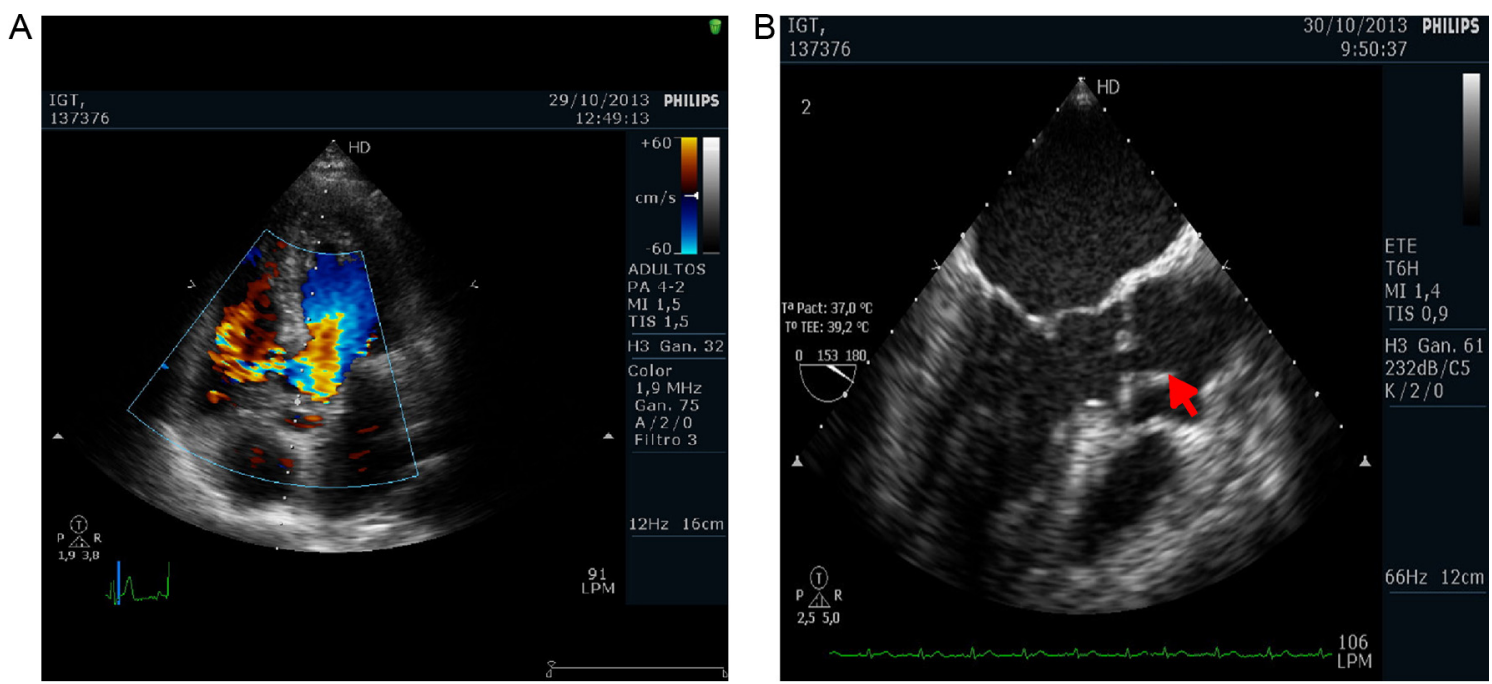

Figura 2 A) Imagen de ETT con Doppler color de la comunicación interventricular. B) vegetación (flecha) sobre la válvula aórtica en ETE. 
en paciente en hemodiálisis con fístula arteriovenosa ${ }^{4}$. En el resto de la bibliografía encontrada, las lesiones asentaban sobre cavidades derechas, o bien, sobre el propio defecto de la membrana interventricular ${ }^{5-9}$. Radiológicamente, los embolismos sépticos suelen ser bilaterales, subpleurales, de predominio en bases y con tendencia a la cavitación. En nuestro caso, el embolismo paradójico se produjo al incidir el chorro de regurgitación a través de la CIV con el consiguiente paso de gérmenes a la circulación menor.

Está indicado iniciar de inmediato el tratamiento antibiótico empírico en caso de El aguda, y en la subaguda cuando existen complicaciones, infección de otra localización o afección importante del estado general. La pauta de tratamiento antibiótica definitiva y su duración dependen del microorganismo aislado y su antibiograma, la válvula afecta y la situación basal del paciente ${ }^{10}$.

\section{Bibliografía}

1. Fernández-Hidalgo N, Tornos P. Epidemiología de la endocarditis infecciosa en España en los últimos 20 años. Rev Esp Cardiol. 2013;66:728-33.

2. Murdoch DR, Corey GR, Hoen B, et al. Clinical presentation, etiology and outcome of infective endocarditis in the 21st Century: The International Collaboration on EndocarditisProspective Cohort Study. Arch Intern Med. 2009;169: 463-73.

3. Aguilar JA, Summerson C. Ventricular septal defect and aortic valvular endoarteritis, cause of systemic and pulmonary embolism. Arch Cardiol Mex. 2005;75:371-2.

4. Rocha JL, González-Roncero F, López-Hidalgo R, et al. Inverse paradoxical embolism in a patient on chronic hemodialysis with aortic bacterial endocarditis. Am J Kidney Dis. 1999;34: 338-40.
5. Byramji A, Gilbert JD, Byard RW. Sudden death as a complication of bacterial endocarditis. Am J Forensic Med Pathol. 2011;32:140-2.

6. Fukumitsu K, Suzuki Y. A septic pulmonary embolism associated with right-sided infective endocarditis and a ventricular septal defect in a patient with atopic dermatitis [Article in Japanese]. Kansenshogaku Zasshi. 2012;86:282-6.

7. Nakauchi Y, Taniguchi M, Miyamura Y, et al. Pulmonary septic embolism with right side infectious endocarditis and ventricular septal defect: A case report. J Cardiol. 2007;50:383-7.

8. Lahdhili H, Ghodbane W, Ziadi M, et al. Aortic endocarditis complicated with a large ventricular septal defect and septic pulmonary embolism. Tunis Med. 2007;85:600-3.

9. Tejirian T, Abbas MA. Bacterial endocarditis following rubber band ligation in a patient with a ventricular septal defect: Report of a case and guideline analysis. Dis Colon Rectum. 2006;49:1931-3.

10. Mensa J, Gatell JM, García-Sánchez JE, et al. Guía de terapéutica antimicrobiana. Barcelona: Ed. Antares; 2013.

Ana Pascual-Bielsa a,*, Miguel Ángel Santolaria-López ${ }^{\mathrm{b}}$, Eva Moreno-Esteban ${ }^{c}$, Guillermo Pinillos-Francia ${ }^{c}$ e Yojana García-Carrascal ${ }^{\text {b }}$

\section{a Servicio de Medicina Intensiva, Hospital Clínico Universitario Lozano Blesa, Zaragoza, España b Servicio de Neumología, Hospital Clínico Universitario Lozano Blesa, Zaragoza, España c Servicio de Cardiología, Hospital Clínico Universitario Lozano Blesa, Zaragoza, España}

* Autor para correspondencia. C/ Condes de Aragón, 8, $3^{\circ} \mathrm{D}$, 50009 Zaragoza, España. Teléfono: 676291132.

Correo electrónico: apasb@hotmail.com (A. Pascual-Bielsa).

http://dx.doi.org/10.1016/j.acmx.2016.05.010 